See discussions, stats, and author profiles for this publication at: https://www.researchgate.net/publication/264001076

\title{
Vessel Identification study for non-coherent high-resolution radar
}

Conference Paper · October 2013

DOI: 10.1109/CCST.2013.6922052

CITATION

1

4 authors, including:

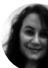

Cristina Carmona-Duarte

Universidad de Las Palmas de Gran Canaria

44 PUBLICATIONS 199 CITATIONS

SEE PROFILE

Some of the authors of this publication are also working on these related projects:

Project CWLFM Radar for Ship Detection and Identification View project

Project Application of the Lognormal Model to the Vocal Tract Movement View project
B.P. Dorta-Naranjo

Universidad de Las Palmas de Gran Canaria

56 PUBLICATIONS 360 CITATIONS

SEE PROFILE 


\title{
Vessel Identification Study for Non-Coherent High- Resolution Radar
}

\author{
Cristina Carmona-Duarte $^{(1)}$, Miguel Ángel Ferrer-Ballester ${ }^{(2)}$, Jaime Calvo-Gallego ${ }^{(3)}$, B. Pablo Dorta-Naranjo ${ }^{(4)}$. \\ ${ }^{(1,2,4)}$ Instituto Universitario para el Desarrollo Tecnológico y \\ la Innovación en comunicaciones (IDeTIC) \\ University of Las Palmas de Gran Canaria \\ Las Palmas, Spain \\ (1) ccarmona@idetic.eu, ${ }^{(2)}$ mferrer@dsc.ulpgc.es, \\ (4)pdorta@dsc.ulpgc.es \\ ${ }^{(3)}$ Department of Computing and Automatics, \\ University of Salamanca \\ Zamora, Spain \\ jaime.calvo@usal.es
}

\begin{abstract}
This paper presents a vessel identification study based on vessel profile. The study was developed with real data obtained with high-resolution Continuous Wave Lineal Frequency Modulated (CW-LFM) radar. Cases studied in this work are vessels entering and leaving the harbor. Also, in this paper, a comparison between different classification techniques such as Neural Networks, Support Vector Machine and kNearest Neighbor is introduced. The differences between normalization methods are evaluated for each classification technique.
\end{abstract}

\section{Keywords—target identification; high-resolution radar}

\section{INTRODUCTION}

Radar is a useful tool for security, allowing terrestrial, maritime and aerial moving target detection and tracking. Recently, the radar bandwidth has been increased to $2 \mathrm{GHz}$ [1] allowing a greater target detection range resolution.

In the case of coast surveillance such as harbor traffic control or open sea fish-farm security, it is necessary not only to detect and track the target but also to identify it in order to present evidence before the court of any acts of sabotage, theft, etc. in private areas.

One way of carrying out vessel identification has been with two-dimensional images obtained from the Radar Doppler image. To apply Doppler to high-resolution radar presents the problem that the computational load increases with the radar resolution, reducing the ability of a real time application. Also for moving targets, Doppler spreading caused by migration through resolution cells usually arises [2].

To allow real time identification taking advantage of the higher radar resolution this paper proposes using onedimensional target profile instead of Doppler image for target identification. We deal with the different profiles obtained due to vessel motion: pitch, roll, and yaw and the position angle with respect to the radar.

The paper is organized as follows. In Section II, first the KBand High-Resolution Homodyne Continuous Wave Lineal Frequency Modulated (CWLFM) radar prototype is presented. Second, the database used for the experiment is detailed. Third, in section IV the problem is presented. Finally in Section V a comparison between different classification techniques is introduced. The differences between normalization methods are evaluated for each classification technique.

\section{K-BAND CWLFM RADAR}

The CWLFM radars are well known [3], however new technologies (e.g. those based on HBTS, HEMTs) allow more power in transmission and less noise in reception in the millimeter band. Working at higher frequencies makes the use of wider bandwidths possible, increasing the information about the target's presence, location and identity.

CWLFM systems utilize an active correlation process that consists of mixing the signal echoes with a replica of the transmitted signal, followed by a bank of filters. Mixing the received signal with the replica, distance information is converted to frequency domain, in such a way that each filter is equivalent to a distance cell. Fig. 1 shows the homodyne CWLFM radar prototype developed [4]. This prototype is a radar environments data capture system, with short medium range coverage $(15 \mathrm{Km})$. Implementation requires a $400 \mathrm{~Hz}$ sweep control signal, $500 \mathrm{MHz}$ bandwidth, and $14.5 \mathrm{GHz}$ central frequency VCO. VCO output is multiplied by two, to meet a $1 \mathrm{GHz}$ bandwidth $(0.15 \mathrm{~m}$ range resolution $)$. Once amplified, the signal is transmitted, and when a target is found the receiver antenna captures its echo. The received signal is mixed with the transmitted signal. This way the IF signal is obtained and then filtered and amplified. A data acquisition card in a PC captures the resulting IF signal. A non-coherent signal for a static spot target at a distance $r_{o}$ from the radar is given by:

$$
d_{q}(n)=A \cos \left[\frac{2 \pi f_{m} r_{0}}{f_{s} \Delta r_{o}} n\right]+n_{q}(n)
$$

where $\mathrm{A}$ is the received signal amplitude, $f_{m}$ the modulation frequency, $f_{s}$ the sampling frequency, $n_{q}(n)$ Gaussian noise, $r_{\mathrm{o}}$ the distance to the nearest point of the target reflector (Fig. 2) and $\Delta r_{o}$ is the Radar resolution which depends on the radar $\operatorname{VCO}\left(\Delta f_{m}\right)$ bandwidth and light speed $(c)$ and it is equal to:

$$
\Delta r_{o}=\frac{c}{2 \Delta f_{m}}
$$




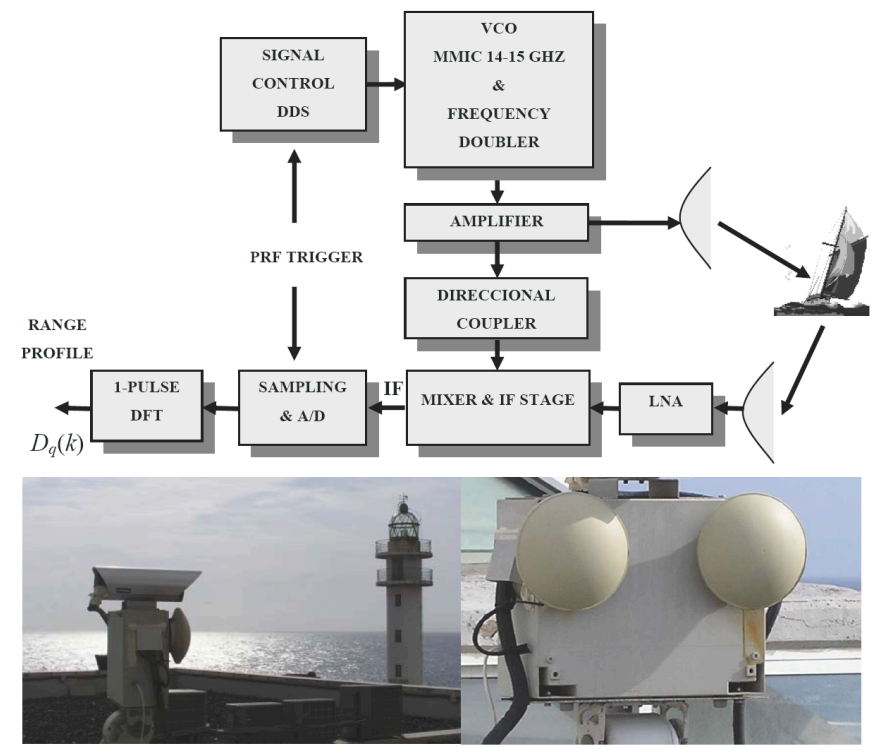

Fig.1. Block diagram and photos of the experimental Linear CWLFM radar system.

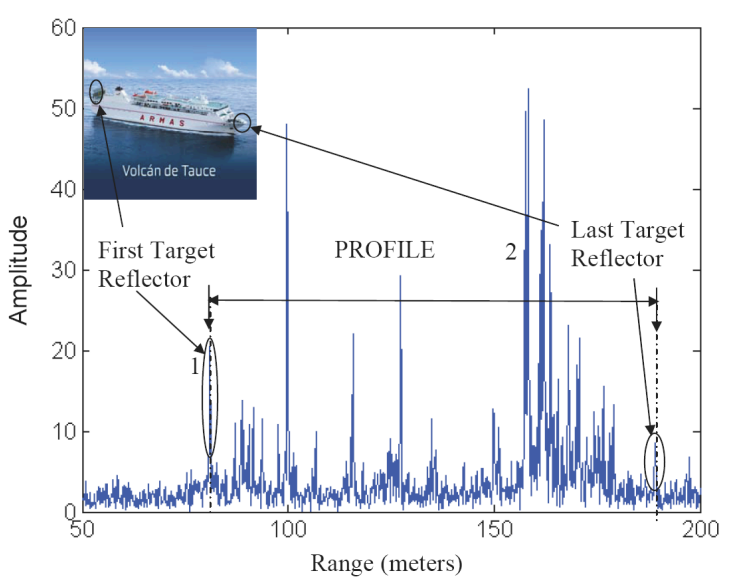

Fig 2. Range profile of real target (120 m length ferry) and target reflector example.

Finally, the digitalized IF signal (1) is Fourier transformed in order to obtain the range profile (Fig.2).

\section{DATABASE ACQUISITION}

For security applications of the radar, a real database is necessary in order to achieve vessel identification. With this in mind, the radar prototype presented in this paper allows us to obtain vessel profiles with a resolution up to $15 \mathrm{~cm}$. The images in Fig. 2 and Fig. 3 have been obtained with the radar working just as explained in Section II. In the $\mathrm{X}$ axis the reflector distance to the radar is represented in meters and in the $\mathrm{Y}$ axis the amplitude $(\mathrm{dB})$ is shown.

The real database contains 400 high-resolution radar profiles of seven different ships taken in different sea states (from 1 to 5), distances and position angles with respect to the radar. Fig. 3 shows the differences between two ferries. Fig. 4 shows the different photos of a ferry going out of the harbor. Fig. 5 shows some of the automatically aligned vessel profiles
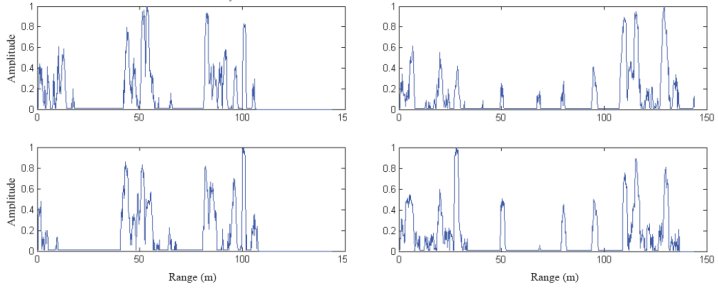

Fig 3. Profiles from ferries: "Volcán de Tejeda" (left) and "Volcán de Timanfaya" (right)

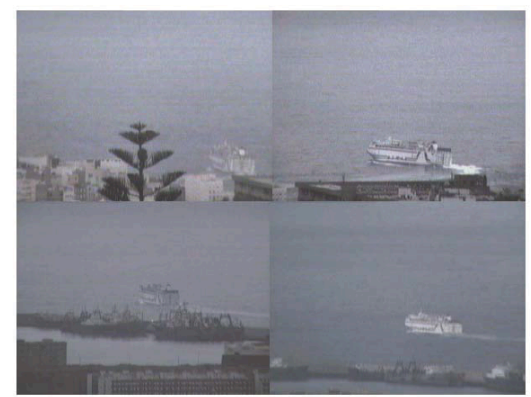

Fig.4. Ferry goes out of the harbor.

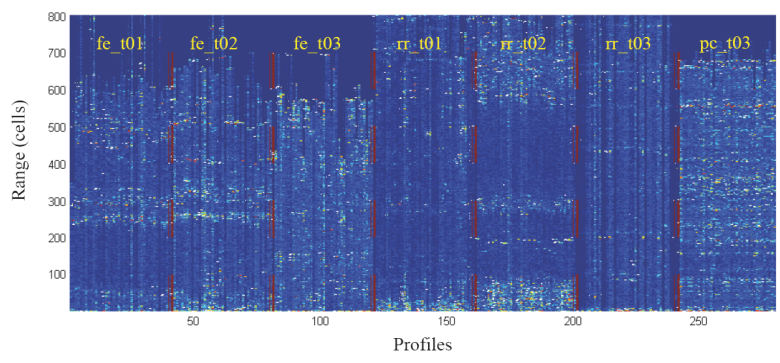

Fig.5. Profiles from different type of vessels.

used in this study. In this figure the nomenclature "fe" means ferry and "t 01 " means that is a type 1 ferry. Also "rr" means ro-ro and "pc" is container vessel. In this figure, the $\mathrm{Y}$ axis is the reflector distance to the radar in meters and in the $\mathrm{X}$ axis the different vessel profiles are shown.

\section{PROBLEM PRESENTATION}

Once the profiles are automatically aligned, the problem is to select the best classification technique to get the best result. The automatic alignment method consists of selecting the first target peak detected, and using this point as the beginning of the profile. In order to select the most adequate classification technique for vessel identification, studies with Neural Networks (NN) [5], Support Vector Machine (SVM) [6] and kNearest Neighbor (KNN) [7] have been carried out.

As the received signals have different amplitude levels due to the varying distance of the radar from the target, amplitude normalization is necessary. The SNR vessel profile varies between 15 and $20 \mathrm{~dB}$.

For each classification technique, three different normalization methods were used: maximum, energy and by limiting the signal level. 
- Maximum normalization consists of dividing each profile amplitude level by the maximum level in each profile:

$$
F_{\max }=\max \{x(n)\}
$$

- Energy normalization is obtained by dividing the amplitude values by the profile energy value. This profile energy is given by:

$$
F_{\text {ener }}=\sqrt{\frac{1}{N} \sum_{n=1}^{N} x(n)^{2}}
$$

- The last method used was to limit all profile signals with a threshold and divided it by the same threshold.

\section{RESULTS}

In this section, first the results for the different identification and normalization techniques are presented. Second, the results for training SVM being first each vessel a class and second each vessel category a class. And finally, the experiment was to change the profile length used for training and test.

For each classifier-training phase, 40 random profiles of each vessel model were used. In the test phase 600 profiles were employed. The results for KNN, NN and SVM are shown in Table I, Table II and Table III respectively. These results were obtained after repeating the training and test process 100 times. The profiles were randomly selected each time.

Table I shows the KNN classification results for different normalization methods and without normalization. We can see the best results for energy normalization with $70.59 \%$ of mean recognition and an equal error rate (EER) of $0.81 \%$.

In the NN study (Table II) the Matalb Toolbox was used for implementation. In this case the results are $20 \%$ better than for KNN. For NN the best results are with the maximum normalization method with a $91 \%$ mean recognition and an EER of $1.41 \%$. Maximum normalization improved by 10 percentage points.

Table III shows the SVM results (SVMlight for Matlab Version 4.00 by Anton Schwaighofer). The best normalization results were for energy normalization with the KNN. Therefore, SVM is less affected by the normalization method than $\mathrm{NN}$ and KNN. The differences between normalization methods were lower than $2 \%$. The mean recognition rate obtained by SVM was $91 \%$, the same as $\mathrm{NN}$, but the mean equal error rate was lower $(0.95 \%)$ than for $\mathrm{NN}$.

Table IV shows the confusion results for SVM with the energy normalization. We can see the greatest error rate was for twin ferries 1 and 2. However, we can see how the mean recognition rates are $84 \%$ and $75 \%$ respectively. This means that it is possible to identify the twin ferries by 400 profile range-sample (Fig. 6). For the other vessels the mean recognition rate is higher than $94.5 \%$. For these reasons SVM is the classification method with best vessel identification results.
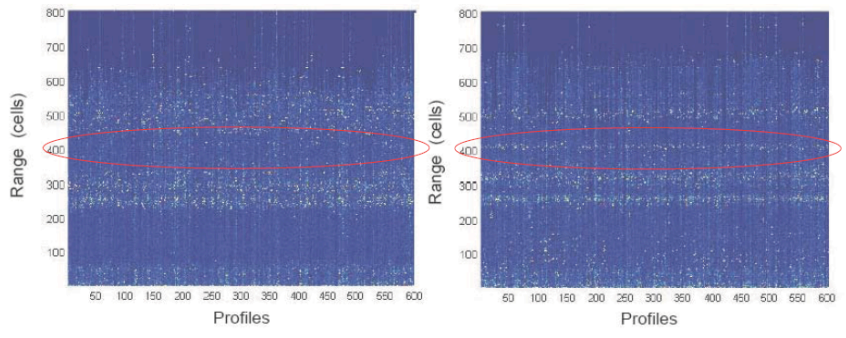

Fig. 6. Automatic profile alignment from twin ferries "Volcán de Tejeda" (left) and "Volcán de Tauce" (right).

TABLE I. THE KNN CLASSIFICATION RESULTS FOR DIFFERENT

\begin{tabular}{|c|c|c|c|c|c|c|c|c|c|}
\hline \multirow[b]{2}{*}{$\begin{array}{l}\text { NORMALIZATION } \\
\text { METHOD }\end{array}$} & \multicolumn{7}{|c|}{ VESSEL TYPE } & \multicolumn{2}{|c|}{ RECOGNITION RATE } \\
\hline & $\begin{array}{c}\text { fe_t01 } \\
(\%)\end{array}$ & $\begin{array}{c}\text { fe_t02 } \\
(\%)\end{array}$ & $\begin{array}{c}\left.\mathrm{fe}_{(\%)} \mathrm{t}\right) \\
(\%)\end{array}$ & $\begin{array}{l}\mathrm{rr}_{(\%)} \mathrm{t01} \\
(\%)\end{array}$ & $\begin{array}{c}\mathrm{rr}_{(\%)} \mathrm{t02} \\
(\%)\end{array}$ & $\begin{array}{c}\mathrm{rr}^{\mathrm{r}} \mathrm{t} 03 \\
(\%)\end{array}$ & $\begin{array}{c}\text { pc_to3 } \\
(\%)\end{array}$ & \begin{tabular}{|c|}
$\begin{array}{c}\text { Successes } \\
\text { mean(\%) } \\
\text { /std }\end{array}$ \\
\end{tabular} & $\begin{array}{l}\text { EER } \\
\text { mean(\%) } \\
/ \text { std }\end{array}$ \\
\hline Amplitude & 37.63 & 19.88 & 21.43 & 54.98 & 28.98 & 73.65 & 51.43 & \begin{tabular}{|l|}
$41.14 /$ \\
19.81 \\
\end{tabular} & $\begin{array}{c}4.19 / \\
0.6\end{array}$ \\
\hline Energy & 53.44 & 39.14 & 79.41 & 72.06 & 66.45 & 90.83 & 92.80 & $\begin{array}{c}70.59 / \\
3.98\end{array}$ & $\begin{array}{l}0.811 \\
0.38\end{array}$ \\
\hline Limiter & 18.00 & 12.50 & 85.85 & 1.54 & 6.09 & 38.92 & 60.14 & $\begin{array}{c}31.86 / \\
2.41 \\
\end{array}$ & $\begin{array}{l}0.84 / \\
0.53\end{array}$ \\
\hline $\begin{array}{l}\text { Without } \\
\text { normalization }\end{array}$ & 16.82 & 11.53 & 84.20 & 1.29 & 4.78 & 36.27 & 56.57 & $\begin{array}{l}30.2 / \\
2.36 \\
\end{array}$ & $\begin{array}{l}0.6 / \\
0.4 \\
\end{array}$ \\
\hline
\end{tabular}
NORMALIZATION METHODS AND WITHOUT NORMALIZATION

TABLE II. THE NN CLASSIFICATION RESULTS FOR DIFFERENT

\begin{tabular}{|c|c|c|c|c|c|c|c|c|c|}
\hline \multirow[b]{2}{*}{$\begin{array}{l}\text { NORMALIZATION } \\
\text { METHOD }\end{array}$} & \multicolumn{7}{|c|}{ VESSEL TYPE } & \multicolumn{2}{|c|}{ RECOGNITION RATE } \\
\hline & $\begin{array}{c}\text { fe_t01 } \\
(\%)\end{array}$ & $\begin{array}{c}\text { fe_t02 } \\
(\%)\end{array}$ & $\begin{array}{c}\text { fe_t } 03 \\
(\%)\end{array}$ & $\begin{array}{l}\mathrm{rr}_{(\%)} \mathrm{t} 01 \\
(\%)\end{array}$ & $\begin{array}{c}\mathrm{rr}_{(\%)} \mathbf{t 0 2} \\
(\%)\end{array}$ & $\begin{array}{c}\text { rr_t03 } \\
(\%)\end{array}$ & $\begin{array}{c}\text { pc } 103 \\
(\%)\end{array}$ & $\begin{array}{c}\text { Successes } \\
\text { mean(\%) } \\
\text { /std }\end{array}$ & $\begin{array}{c}\text { EER } \\
\text { mean(\%) } \\
\text { /std }\end{array}$ \\
\hline Amplitude & 86.07 & 78.29 & 91.10 & 91.50 & 98.42 & 96.12 & 95.55 & $\begin{array}{l}91 / \\
2.6 \\
\end{array}$ & $\begin{array}{l}1.41 / \\
0.22 \\
\end{array}$ \\
\hline Energy & 63.67 & 55.29 & 70.78 & 84.84 & 91.68 & 89.78 & 88.19 & $\begin{array}{c}77.74 / \\
5.6\end{array}$ & $\begin{array}{l}1.12 / / \\
0.32\end{array}$ \\
\hline Limiter & 79.11 & 66.06 & 94.71 & 89.26 & 96.39 & 94.95 & 96.47 & $\begin{array}{c}88.14 / \\
2.91 \\
\end{array}$ & $\begin{array}{r}0.96 / \\
0.16 \\
\end{array}$ \\
\hline
\end{tabular}
NORMALIZATION METHODS.

TABLE III. THE SVM CLASSIFICATION RESULTS FOR DIFFERENT

\begin{tabular}{|c|c|c|c|c|c|c|c|c|c|}
\hline \multirow[b]{2}{*}{$\begin{array}{l}\text { NORMALIZATION } \\
\text { METHOD }\end{array}$} & \multicolumn{7}{|c|}{ VESSEL TYPE } & \multicolumn{2}{|c|}{ RECOGNITION RATE } \\
\hline & $\begin{array}{l}\text { fe_to1 } \\
(\%)\end{array}$ & $\begin{array}{c}\text { fe_t02 } \\
(\%)\end{array}$ & $\begin{array}{c}\mathrm{fe}_{(\%)} \mathrm{t} 03 \\
(\%)\end{array}$ & $\begin{array}{c}\mathrm{rr}_{(\%)} \mathbf{t 0 1} \\
(\%)\end{array}$ & $\begin{array}{c}\mathrm{rr}_{(\%)} \mathbf{t 0 2} \\
(\%)\end{array}$ & $\begin{array}{c}\text { rr_t03 } \\
(\%)\end{array}$ & $\begin{array}{c}\text { pc_t03 } \\
(\%)\end{array}$ & $\begin{array}{c}\text { Successes } \\
\text { mean }(\%) \\
/ \text { std }\end{array}$ & $\begin{array}{c}\text { EER } \\
\text { mean(\%) } \\
/ \text { std } \\
\end{array}$ \\
\hline Amplitude & 83 & 75.01 & 93.97 & 89.15 & 98.26 & 94.98 & 96.14 & $\begin{array}{c}90.07 / \\
3.04 \\
\end{array}$ & $\begin{array}{l}1.01 / \\
0.16 \\
\end{array}$ \\
\hline Energy & 83.61 & 75.19 & 95.58 & 91.29 & 97.86 & 95.24 & 98 & $\begin{array}{c}91 / \\
2.78 \\
\end{array}$ & $\begin{array}{l}0.95 / \\
0.14\end{array}$ \\
\hline Limiter & 82.49 & 71.38 & 95.22 & 89.66 & 97.52 & 94.78 & 97.11 & $\begin{array}{c}89.73 / \\
2.89\end{array}$ & $\begin{array}{l}1.03 / \\
0.16\end{array}$ \\
\hline
\end{tabular}
NORMALIZATION METHODS AND WITHOUT NORMALIZATION

Another experiment was vessel type classification. This means that the vessels are classified into three categories: ferry, container and ro-ro. Table $\mathrm{V}$ shows the results from the training process by vessels like in table III, and then the classification by vessel categories. We can see how the mean recognition rate increased to $97,6 \%$ and the equal error rate decreased to $0.57 \%$. The experiment was then repeated but the training process was only done with the three categories. Table VI shows how the mean recognition rate decreased to $88,1 \%$ and the equal error rate increased to $10,51 \%$. For this reason it is better to train SVM for each particular vessel independently. 
TABLE IV. THE CONFUSION TABLE FOR SVM WITH THE ENERGY NORMALIZATION.

\begin{tabular}{|c|c|c|c|c|c|c|c|}
\hline & $\begin{array}{c}\text { fe_to1 } \\
(\%)\end{array}$ & $\begin{array}{c}\text { fe_t02 } \\
(\%)\end{array}$ & $\begin{array}{c}\text { fe_t03 } \\
(\%)\end{array}$ & $\begin{array}{c}\text { rr_t01 } \\
(\%)\end{array}$ & $\begin{array}{c}\text { rr_t02 } \\
(\%)\end{array}$ & $\begin{array}{c}\text { rr_t03 } \\
(\%)\end{array}$ & $\begin{array}{c}\text { pc_to3 } \\
(\%)\end{array}$ \\
\hline fe_t 01 & 83.61 & 10.56 & 0.97 & 4.5 & 0.2 & 1.9 & 0.8 \\
\hline fe_t02 & 13.24 & 75.19 & 8.92 & 0.8 & 0.4 & 1.5 & 1.2 \\
\hline fe_t03 & 0.98 & 4.53 & 95.58 & 0.008 & 0.003 & 0.04 & 1 \\
\hline rr_t01 & 0.99 & 1.05 & 0.003 & 91.29 & 3.08 & 0.01 & 0.4 \\
\hline rr_t02 & 0.09 & 0.1 & 0.3 & 1.39 & 97.86 & 1.39 & 0.002 \\
\hline rr_t03 & 0.07 & 0.48 & 1.7 & 0.74 & 0.49 & 95.24 & 0.14 \\
\hline pc_t03 & 0.81 & 1.2 & 0.02 & 0 & 0 & 0 & 98 \\
\hline
\end{tabular}

The last experiment was to change the profile length used for training and testing. Table VII shows results using 600, 900 and 2000 profile samples. We can see that the best mean recognition rate is for longer profile length. But we can also see that for 600 sample length, the recognition rate only decreased by 4 percentage points and the equal error rate remained the same.

\section{CONCLUSION}

With the aid of high-resolution radar and SVM classification technique, real vessel identification is possible.

For good identification it is necessary to select a normalization method suitable for each classification technique. From this study we can see that the SVM technique with energy normalization has the best results. Profile length is not an important factor in correct vessel identification. Also, it is possible to see that in the training process it is better to use one model for each vessel type than one model for each vessel.

\section{ACKNOWLEDGMENT}

This work was supported by the Ministerio de Economía y Competitividad (TEC2010-21217-C02-01) and ESF / European Social Fund. We also want to thank the participation from the "Instituto Canario de Ciencias Marinas".

TABLE V. THE CONFUSION TABLE BY VESSEL CATEGORY TRAINING WITH VESSEL.

\begin{tabular}{|l|c|c|c|}
\cline { 2 - 4 } \multicolumn{1}{c|}{} & $\begin{array}{c}\text { Ferry } \\
(\%)\end{array}$ & $\begin{array}{c}\text { Ro-ro } \\
(\%)\end{array}$ & $\begin{array}{c}\text { Container } \\
(\%)\end{array}$ \\
\hline Ferry & 98 & 1.03 & 1.02 \\
\hline Ro-ro & 0.53 & 97.1 & 0.17 \\
\hline Container & 0.67 & 0 & 98 \\
\hline \multicolumn{4}{|c|}{ Mean recognition: $\mathbf{9 7 . 6 \%}$} \\
EER: $0.57 \%$
\end{tabular}

TABLE VI. CONFUSION TABLE BY VESSEL CATEGORY TRAINING WITH VESSEL CATEGORIES.

\begin{tabular}{|l|c|c|c|}
\cline { 2 - 4 } \multicolumn{1}{c|}{} & $\begin{array}{c}\text { Ferry } \\
(\%)\end{array}$ & $\begin{array}{c}\text { Ro-ro } \\
(\%)\end{array}$ & $\begin{array}{c}\text { Container } \\
(\%)\end{array}$ \\
\hline Ferry & 87.07 & 17.16 & 5.52 \\
\hline Ro-ro & 18.44 & 80.76 & 12.89 \\
\hline Container & 1.90 & 7.15 & 96.34 \\
\hline \multicolumn{3}{|c|}{ Mean recognition: $\mathbf{8 8 . 1 \%}$} \\
EER: $\mathbf{1 0 . 5 1 \%}$
\end{tabular}

TABLE VII. RESULTS BY LENGTH.

\begin{tabular}{|c|c|c|c|c|c|c|c|c|c|}
\hline & \multicolumn{7}{|c|}{ VESSEL TYPE } & \multicolumn{2}{|c|}{ RECOGNITION RATE } \\
\hline $\begin{array}{l}\text { PROFILE } \\
\text { LENGTH } \\
\text { (CELLS) }\end{array}$ & $\begin{array}{c}\text { fe_t }_{-} 01 \\
(\%)\end{array}$ & $\begin{array}{c}\text { fe_t02 } \\
(\%)\end{array}$ & $\begin{array}{c}\mathrm{fe}_{-} \mathrm{t} 03 \\
(\%)\end{array}$ & $\begin{array}{c}\mathrm{rr}_{-} \mathrm{t} 01 \\
(\%)\end{array}$ & $\begin{array}{c}\mathrm{rr}_{-} \mathrm{t} 02 \\
(\%)\end{array}$ & $\begin{array}{c}\mathrm{rr}_{-} \mathbf{t 0 3} \\
(\%)\end{array}$ & $\begin{array}{c}\text { pc_t03 } \\
(\%)\end{array}$ & $\begin{array}{c}\text { Successes } \\
\text { mean }(\%) \\
\text { /std }\end{array}$ & $\begin{array}{c}\text { EER } \\
\text { mean }(\%) \\
/ \text { std }\end{array}$ \\
\hline 600 & 79.21 & 77.99 & 86.80 & 87.29 & 96.99 & 91.94 & 93.32 & $\begin{array}{c}87.65 / \\
3.46\end{array}$ & $\begin{array}{l}0.91 / 1 \\
0.14\end{array}$ \\
\hline 900 & 82.15 & 75.43 & 89.51 & 88.93 & 98.27 & 94.16 & 94.86 & $\begin{array}{c}89.05 / \\
3.19\end{array}$ & $\begin{array}{c}0.96 / \\
0.14\end{array}$ \\
\hline 2000 & 83.62 & 75.19 & 95.58 & 91.29 & 97.86 & 95.24 & 98.00 & $\begin{array}{c}91 / \\
2.78\end{array}$ & $\begin{array}{c}0.95 / \\
0.14 \\
\end{array}$ \\
\hline
\end{tabular}

\section{REFERENCES}

[1] Carmona-Duarte, C., Dorta Naranjo, B.P., Lopez, A.A., del Campo, A.B., "CWLFM radar for ship detection and identification," IEEE Aerospace and Electronic Systems Magazine, Vol. 22, Issue 2, pp. 2226, 2007.

[2] Munoz-Ferreras, J. M., J. Calvo-Gallego, F. Perez-Martinez, A. Blancodel-Campo, A. Asensio-Lopez, and B. P. Dorta-Naranjo, "Motion compensation for ISAR based on the shift and convolution algorithm," Proc. IEEE Radar Conference, 366-370,Verona, NY, USA, 2006.

[3] Merrill Skolnik, "Radar Handbook", 2nd ed., Mc Graw-Hill, 1990.

[4] A. Asensio, A. Blanco-del-Campo, J. Gismero-Menoyo, D. RamírezMorán, G. Torregrosa-Penalva, B.P. Dorta-Naranjo and C. CarmonaDuarte. "High Range-Resolution Radar Scheme for imaging with tunable Distance Limits", Electronic Letters, Volume 40, Number 17, August 2004

[5] R. Gil-Pita, P. Jarabo-Amores, M. Rosa-Zurera, F. Lopez-Ferreras, "Improving neural classifiers for ATR using a kernel method for generating synthetic training sets", 12th IEEE Workshop on Neural Networks for Signal Processing, pp. 425 - 434, 4-6 September 2002.

[6] Xiao Huaitie, Guo Lei, Fu Qiang, "Radar Target Recognition Method Using Improved Support Vector Machines Based on Polarized HRRPs", International Conference on Computational Intelligence and Security, Vol. 1, pp. 702 - 707, November 2006

[7] J. A. Malas, , K. M. Pasala, J. Westerkamp, "Automatic target classification of slow moving ground targets in clutter", IEEE Transactions on Aerospace and Electronic Systems, Vol. 40, No. 1, 190205, 2004 